\title{
Hyperglycaemia, hypertension and their risk factors among Palestine refugees served by UNRWA
}

\author{
H.S.A. Mousa, ${ }^{7}$ S. Yousef, ${ }^{1}$ F. Riccardo, ${ }^{7}$ W. Zeidan ${ }^{7}$ and G. Sabatinelli ${ }^{1}$
}

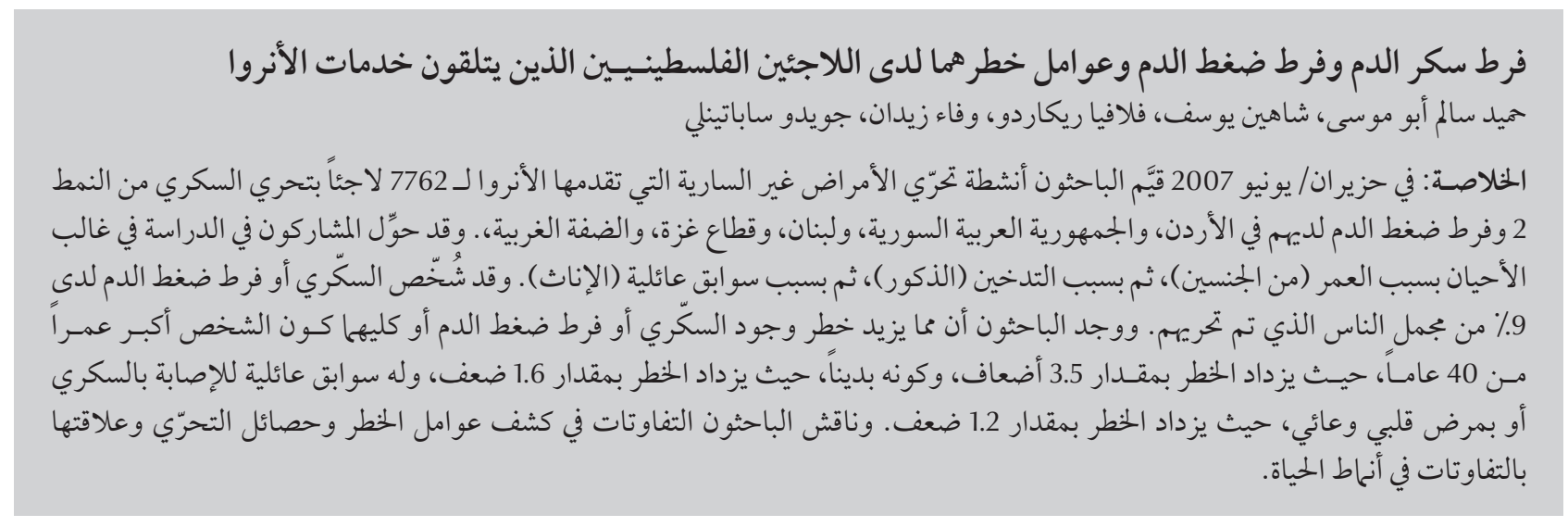

ABSTRACT UNRWA's noncommunicable disease screening activities were evaluated among 7762 refugees screened for hypertension and type 2 diabetes in Jordan, Syrian Arab Republic, Lebanon, Gaza Strip and West Bank in June 2007. People were referred for screening most commonly because of age (both sexes), followed by smoking (males) and family history (females). A total of $9 \%$ of screened people were diagnosed with hypertension/ diabetes. Being older than 40 years, obese or with a positive family history of diabetes or cardiovascular disease increased the risk of presenting with hypertension and/or hyperglycaemia 3.5, 1.6 and 1.2 times respectively. Differences in risk factor detection and screening outcome in relation to differences in lifestyle are discussed.

\section{Hyperglycémie, hypertension artérielle et facteurs de risque de ces maladies chez les réfugiés palestiniens} pris en charge par I'UNRWA

RÉSUMÉ Les activités de dépistage des maladies non transmissibles de l'Office de secours et de travaux des Nations Unies pour les réfugiés de Palestine dans le Proche-Orient UNRWA) ont été évaluées auprès de 7762 réfugiés ayant fait l'objet d'un dépistage de l'hypertension artérielle et du diabète de type 2 en Cisjordanie, à Gaza, en Jordanie, au Liban et en République arabe syrienne en juin 2007. Les patients ont été orientés vers ce dépistage principalement en raison de leur âge (pour les deux sexes), mais également pour cause de tabagisme (hommes) ou d'antécédents familiaux (femmes). Au total, un diagnostic d'hypertension artérielle et/ou de diabète a été établi chez $9 \%$ des personnes examinées. Le fait d'avoir plus de 40 ans, d'être obèse ou de présenter des antécédents familiaux de diabète ou de maladie cardiovasculaire multiplie le risque d'hypertension artérielle ou d'hyperglycémie par 3,5, 1,6 et 1,2, respectivement. Cette étude traite également des disparités liées aux différences d'hygiène de vie en termes de détection des facteurs de risque et de résultat du dépistage.

${ }^{7}$ Department of Health, Headquarters, United Nations Reliefand Works Agency for Palestine Refugees in the Near East, Amman, Jordan (Correspondence to F. Riccardo:f.riccardo@unrwa.org).

Received: 02/04/08; accepted: 22/07/08 


\section{Introduction}

Attention is increasingly being paid to noncommunicable diseases (NCDs) in low- and middle-income countries. Diseases such as cardiovascular disease (CVD), diabetes and cancer now account for $70 \%$ of the adult burden of disease in middle-income countries, not far behind the recorded burden of disease in developed countries of $80 \%$. If the current trend is maintained, by 2020 NCDs will account for $80 \%$ of the global burden of disease [1].

UNRWA, the United Nations Relief and Works Agency for Palestine Refugees in the Near East, was established in 1949 by the United Nations General Assembly to carry out direct relief and works programmes for Palestine refugees. Operating in a context characterized by chronic political instability and a worsening socioeconomic situation, UNRWA is unique in terms of its long-standing commitment to one group of refugees and has contributed to the welfare and human development of 4 generations of Palestine refugees.

As part of the disease prevention and control sub-programme UNRWA has been promoting primary, secondary and tertiary prevention of NCDs since 2005. Due to constraints in financial and human resources, the interventions only target hypertension and type 2 diabetes mellitus.

\section{Methods}

At the time of the study UNRWA's 129 primary health care facilities offered health services to 4.6 million registered Palestinian refugees in Jordan, Lebanon, Syrian Arab Republic, West Bank and the Gaza Strip. In 2006 the estimated total population served by the primary health care services was 3.2 million people, accounting for $73 \%$ of the registered refugee population at the time.

Screening for NCDs at UNRWA clinics is offered to all people aged 40 years or over attending health clinics either as patients or accompanying family members. Individuals presenting with risk factors associated with diabetes and/or hypertension are encouraged to undergo screening even if they are below 40 years old. These risk factors included obesity (body mass index $\geq 30 \mathrm{~kg} / \mathrm{m}^{2}$ ), history of smoking (>1 year), gestational diabetes and/or hypertension and positive family history of diabetes mellitus and/or CVD. People with random abnormal blood pressure readings $(\geq 140 / \geq 90 \mathrm{mmHg}$ ) or high random glycaemia ( $\geq 126 \mathrm{mg} / \mathrm{dL})$ are referred for further investigation and evaluated for diagnosis. Hypertensive and diabetic patients are then referred to the NCD division of the clinic for registration and medical follow-up.

To assess the detection rate of hypertension and hyperglycaemia and their risk factors among people accessing screening and the outcome of UNRWA's screening activities, a caseseries study was conducted among 7762 people who underwent screening for diabetes and hypertension in June 2007 in 3 UNRWA health centres randomly selected from each area of UNRWA operations (Jordan, Syrian Arab Republic, Lebanon, West Bank and Gaza Strip). Areas of UNRWA operation are referred to in this paper as "fields".

Data were entered and analysed with Epi6 and Analysis (Epi-Info Windows, version 3.4.1). The statistical difference in the distribution of risk factors and outcomes of the screening by field and sex was calculated using the chi-squared test. $P$-values $<0.05$ were considered statistically significant. A multiple logistic regression model was used for the risk factor multivariate analysis. Although there were more women than men in all fields the distribution was not constant and the correlation between sex and field was significant $\left(\chi^{2}=62.3 ; P\right.$ $<0.01)$. For this reason the data analysis was stratified by sex.

\section{Results}

The study population comprised 5317 (68.5\%) females and 2445 (31.5\%) males and the overall mean age was 45.5 (standard deviation 13.9) years.

Due to the screening protocol, age was the main factor that determined the enrolment of patients. However, the proportion of people screened aged $40+$ years varied significantly among areas of operation, from around 50\% in Gaza for both sexes to around 90\% in the West Bank (Table 1). A statistically significant variation among fields was also observed in the proportion of females and males aged 40+ years who were screened (females: $\chi^{2}=636.2, P$ $<0.01$; males: $\left.\chi^{2}=219.4, P<0.01\right)$. The second reason for screening was smoking for males and positive family history of NCDs for females.

Across all fields, $69.2 \%$ of the males and $67.3 \%$ of the females had 2 or more risk factors, with significant variations between the 5 fields for females $\left(\chi^{2}=159.8, P<0.01\right)$ and for males $\left(\chi^{2}=21.2, P<0.01\right)$. Table 1 Distribution of Palestine refugees aged $40+$ years screened for diabetes
and hypertension by United Nations Relief and Works Agency for Palestine Refugees in the Near East

\begin{tabular}{lccc} 
Area of operation & $\begin{array}{c}\text { Males } \\
(\boldsymbol{n}=\mathbf{2 4 4 5}) \%\end{array}$ & $\begin{array}{c}\text { Females } \\
(\boldsymbol{n}=\mathbf{5 3 1 7}) \%\end{array}$ & $\begin{array}{c}\text { Total } \\
(\boldsymbol{n}=\mathbf{7 7 6 2}) \%\end{array}$ \\
Jordan & 76.8 & 77.4 & 77.2 \\
Lebanon & 86.0 & 91.5 & 89.1 \\
Syrian Arab Republic & 70.5 & 50.3 & 55.7 \\
Gaza Strip & 54.2 & 51.9 & 52.6 \\
West Bank & 94.6 & 88.6 & 90.4 \\
\hline
\end{tabular}


As shown in Table 2 the frequency of smoking and obesity varied significantly between the sexes and among fields independently of sex. The highest proportion of obese people was found Jordan (32.7\% of males and 53.7\% of females) and the Occupied Palestinian Territories (34.1\% of males in Gaza and 52.6\% of females in the West Bank) while the lowest proportion in both males and females were observed in Lebanon (22.4\% of males and $38.7 \%$ of females). In Lebanon smoking was widespread among both sexes (59.5\% of males and 39.9\% of females), whereas smoking was reported by a very small number of women in Jordan (8.4\%) and the Occupied Palestinian Territories (0.6\% in Gaza and $6.1 \%$ in West Bank). A statistically significant variation was observed in the number of screened people who reported a positive family history of diabetes and $/$ or CVD by field for females $\left(\chi^{2}=204.2, P<0.01\right)$ and for males $\left(\chi^{2}=53.9, P<0.01\right)$, with the highest proportion of cases in Gaza ( $45.4 \%$ for males and $51.9 \%$ for females). There was no correlation between this risk factor and $\operatorname{sex}\left(\chi^{2}=0.77, P>0.05\right)$.

Being older than 40 years, being obese or having a family history of diabetes and/or CVD increased the risk of developing diabetes or hypertension by 3.5, 1.6 and 1.2 times respectively (Table 3). Moreover, the risk of developing disease increased with increasing number of risk factors in the same person, being 2.7 times the risk in people with 4 risk factors compared with those with only 1 risk factor.

Overall $18.7 \%$ of the screened population presented with high blood pressure ( $\geq 140 / \geq 90 \mathrm{mmHg}$ ), 9.8\% had random blood glucose values $\geq 126 \mathrm{mg} / \mathrm{dL}$ and $17.7 \%$ had random blood cholesterol values $\geq 200 \mathrm{mg} / \mathrm{mL}$ (Table 4). Variations were statistically significant between fields (independently of sex) and between the sexes. Of the people who underwent screening $9.0 \%$ were diagnosed with hypertension and/or diabetes and were referred to the NCD clinics; $13.6 \%$ of these were diagnosed with both conditions. Significant variations were found between fields for females $\left(\chi^{2}=112.6, P<0.01\right)$ and for males $\left(\chi^{2}=39.2, P<0.01\right)$, with the highest proportion of cases diagnosed in the Occupied Palestinian Territories and the lowest in Jordan and the Syrian Arab Republic. Males were diagnosed with NCDs more often than females $\left(\chi^{2}=11, P<0.01\right)$.

\section{Discussion}

For the past 20 years there has been a growing awareness of the burden of NCDs in the Eastern Mediterranean Region (EMR). Among NCDs, diabetes and hypertension share a common pathogenesis and complications. CVDs are the major complication of type 2 diabetes, causing $50 \%$ or more of all deaths from diabetes as well as substantial morbidity [2]. Moreover the prognosis of hypertension is influenced by associated clinical conditions that include diabetes [3].

CVDs are the major cause of illness and death in theEMR, accounting for $31 \%$ of deaths, and almost $26 \%$ of the adult population of the Region is estimated to be affected by hypertension [3-5]. The World Health Organization Regional Office for the Eastern Mediterranean has stated that the adult prevalence rate of diabetes in the EMR ranges from as low as $3.5 \%$ to as high as 30.0\%. [6]. Available estimates suggest

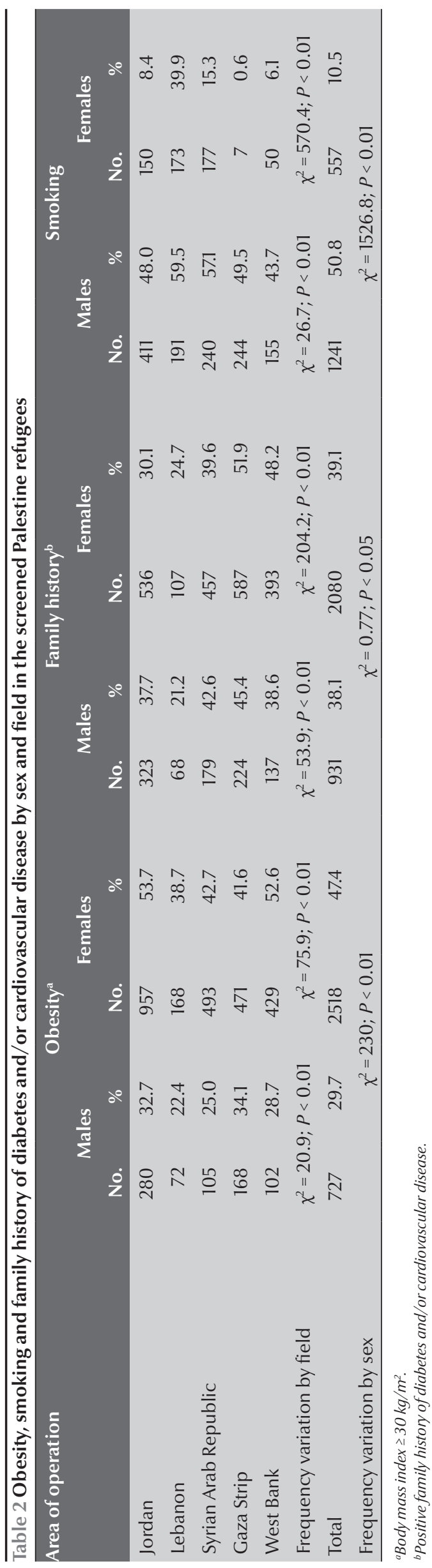




\begin{tabular}{|c|c|c|c|}
\hline Risk factor & Odds ratio & $95 \% \mathrm{CI}$ & $P$-value \\
\hline Family history ${ }^{a}$ & 1.2 & $1.0-1.5$ & $<0.05$ \\
\hline Age $\geq 40$ years & 3.5 & $2.6-4.6$ & $<0.01$ \\
\hline Obesity $^{b}$ & 1.6 & $1.4-1.9$ & $<0.01$ \\
\hline Smoking history & 1.0 & $0.8-1.2$ & $>0.05$ \\
\hline 2 risk factors ${ }^{\mathrm{c}}$ & 1.6 & $1.3-2.0$ & $<0.01$ \\
\hline 3 risk factors ${ }^{\mathrm{c}}$ & 2.3 & $1.9-2.9$ & $<0.01$ \\
\hline 4 risk factors ${ }^{\mathrm{c}}$ & 2.7 & $1.8-4.1$ & $<0.01$ \\
\hline
\end{tabular}

Likelihood ratio P-value $<0.01$.

${ }^{a}$ Positive family history of diabetes and/or cardiovascular disease; ${ }^{b}$ body mass index $\geq 30 \mathrm{~kg} / \mathrm{m}^{2}$; ${ }^{\text {versus }} 1$ risk factor.

$\mathrm{Cl}=$ confidence interval.

that by 2010, 26.6 million people in the Middle East and Northern Africa will be living with diabetes, a number that is expected to double in the next 20 years [7]. Type 2 diabetes is predominant and, as in other regions with a high prevalence of type 2 diabetes, the onset of the disease tends to occur at a relatively young age [8].

The observed epidemiological trend is likely to lead to an increase in the burden of NCDs in future years. The region will have to face the socioeconomic consequences of the growing prevalence of NCD-related disease and the economic burden of a growing number of chronic patients requiring medical care. However, the high cost [9] and long duration of treatments for NCD are not the only issues to be faced in the EMR. The Region is tackling the double burden of communicable and noncommunicable diseases [10] and ultimately this is raising sustainability issues, with disparities in access to treatment between countries and within the same country (according to sex, rural/urban setting and different social and economic status).

The risk factors for diabetes and hypertension used as screening criteria were both modifiable (smoking and obesity) and non-modifiable (family history). Our study shows again that age was the determinant that most strongly correlated with the development of hyperglycaemia or hypertension, increasing the risk 3.5-fold in people aged 40 years or older. The next most important correlates were obesity (1.6-fold higher risk) and family history of diabetes and/ or CVD (1.2-fold higher risk). As be expected, the greater the number of risk factors, the higher the risk of actually being diagnosed with diabetes/hypertension, confirming the need to specifically target people with multiple risk factors during screening initiatives for NCD.

Almost $70 \%$ of the screened population were female, and significant differences in the frequency of risk detection were observed between males and females for all risk factors except family history of diabetes/CVD. Moreover, the differences among fields in risk factor detection and screening outcomes were statistically significant. This is most probably a manifestation of the diverse social and cultural environments to which the refugees are exposed and the different behavioural patterns between the sexes.

Available data from national and subnational surveys conducted in corresponding territories on the prevalence of obesity was compared with the detection rate for obesity in this study (Table 5). Palestine refugees have higher levels of obesity than the population of the host country in Jordan and Lebanon but not in the Syrian Arab Republic, perhaps because society there is predominantly rural and there may be favourable lifestyle factors such as better access to fruits and vegetables. The high frequency of obesity among refugees in the Occupied Palestinian Territories could be related to a lack of attention to healthier lifestyles, including good nutrition and exercise. However, in fields such as Gaza the lower consumption of certain foods could also be influenced by the limitations imposed on movement of people and goods that account for a poorer choice and higher prices in food markets.

The high prevalence of obesity, however, was not a localized phenomenon as it reflects a more generalized change in the nutrition profile of the population

\begin{tabular}{|c|c|c|c|c|}
\hline \multirow[t]{2}{*}{ Parameter } & \multicolumn{2}{|c|}{$\begin{array}{l}\text { Screened } \\
\text { population }\end{array}$} & \multirow{2}{*}{$\begin{array}{c}\text { Frequency variation } \\
\text { stratified } \\
\text { by sex }\end{array}$} & \multirow[t]{2}{*}{$\begin{array}{l}\text { Frequency variation } \\
\text { between sexes }\end{array}$} \\
\hline & No. & $\%$ & & \\
\hline Blood pressure $\geq 140 / \geq 90 \mathrm{mmHg}$ & 1453 & 18.7 & $\begin{array}{l}\text { Females } \chi^{2}=63, P<0.01 \\
\text { Males } \chi^{2}=30.6, P<0.01\end{array}$ & $\chi^{2}=35.6, P<0.01$ \\
\hline Random blood glucose $\geq 126 \mathrm{mg} / \mathrm{dL}$ & 611 & 9.8 & $\begin{array}{l}\text { Females } \chi^{2}=54, P<0.01 \\
\text { Males } \chi^{2}=41, P<0.01\end{array}$ & $\chi^{2}=43.4, P<0.01$ \\
\hline Random blood cholesterol $\geq 200 \mathrm{mg} / \mathrm{mL}$ & 1020 & 17.7 & $\begin{array}{l}\text { Females } \chi^{2}=249, P<0.01 \\
\text { Males } \chi^{2}=11.1, P<0.05\end{array}$ & $\chi^{2}=14.6, P<0.01$ \\
\hline
\end{tabular}




\begin{tabular}{|c|c|c|c|}
\hline Country/population & $\begin{array}{c}\text { Males } \\
\%\end{array}$ & $\begin{array}{c}\text { Females } \\
\%\end{array}$ & Source \\
\hline \multicolumn{4}{|l|}{ Jordan } \\
\hline Host country & 10.3 & 16.2 & 2002 national survey, age $>18$ yrs \\
\hline Palestine refugees ${ }^{\mathrm{a}}$ & 32.7 & 53.7 & UNRWA 2007 \\
\hline \multicolumn{4}{|l|}{ Lebanon } \\
\hline Host country & 14.3 & 18.8 & 1997 national survey, age $>20$ yrs \\
\hline Palestine refugees ${ }^{\mathrm{a}}$ & 22.4 & 38.7 & UNRWA 2007 \\
\hline \multicolumn{4}{|l|}{ Gaza Strip and West Bank } \\
\hline Host country & 30.0 & 50.0 & 2003 survey, Birzeit University \\
\hline Gaza: Palestine refugees ${ }^{a}$ & 34.1 & 41.6 & UNRWA 2007 \\
\hline $\begin{array}{l}\text { West Bank: Palestine } \\
\text { refugees }^{\mathrm{a}}\end{array}$ & 28.7 & 52.6 & UNRWA 2007 \\
\hline \multicolumn{4}{|l|}{ Syrian Arab Republic } \\
\hline Host country (subnational) & 28.8 & 46.4 & 2006 Aleppo survey, age 18-65 yrs \\
\hline Palestine refugees ${ }^{\mathrm{a}}$ & 25.0 & 42.7 & UNRWA 2007 \\
\hline $\begin{array}{l}\text { Israel } \\
\text { Eastern Mediterranean }\end{array}$ & 19.8 & 25.4 & 2001 national survey, age $25-64$ yrs \\
\hline Region & $30-60$ & $35-75$ & Musaiger AO [10] \\
\hline
\end{tabular}

UNRWA = United Nations Relief and Works Agency for Palestine Refugees in the Near East.

${ }^{a}$ Data refer only to the Palestinian refugees screened for noncommunicable diseases at UNRWA health centres.

of the EMR. The Food and Agriculture Organization Regional Office for the Near East analysed the nutritional profile of the region, revealing a 2 -fold increase in energy and protein availability between 1961 and 1990 and a 3 -fold increase in fat availability, with no comparable increase in the availability of vegetables and only a slight increase in the per capita supply of fruits. This resulted in an increase in calorie consumption and an increased prevalence of obesity in the population [1].

The prevalence of tobacco use in the region compared with the smoking detection rate in the UNRWA study showed an opposite trend, with Palestine refugees apparently smoking less than the population of the host country in the Syrian Arab Republic, Lebanon and the West Bank and Gaza Strip (Table 6). However, this could be due to different study designs that may have included tobacco use practices other than cigarette smoking. Specific research on this aspect is currently being carried out.
From a public health perspective, our case-series study strongly suggests that obesity, in particular among women, and smoking, particularly among men, are health priorities in the Palestine refugee population served by UNRWA. For this to be addressed effectively, integration at the community level between educational, curative and preventive interventions is required.

UNRWA's cross-cutting approach to primary health care is certainly an asset in developing activities focusing on NCD prevention in vulnerable communities. The health programme addresses the issue of refugees' health from birth to old age, implementing health prevention and promotion activities at various levels. Moreover, coordination among the health, education and relief programmes brings health education from exclusively medical environments into schools and other community aggregation centres.

The challenges facing UNRWA in the near future are numerous, however.

\begin{tabular}{|c|c|c|c|}
\hline $\begin{array}{l}\text { Table } 6 \text { Prevalence of tobacc } \\
\text { Mediterranean Region and s } \\
\text { Palestine refugees }\end{array}$ & $\begin{array}{l}\text { use in } t \\
\text { noking } \mathrm{d}\end{array}$ & $\begin{array}{l}\text { e hostin } \\
\text { etection }\end{array}$ & $\begin{array}{l}\text { g countries and Eastern } \\
\text { rates in the present study of }\end{array}$ \\
\hline Country/population & Males & Females & Source \\
\hline & $\%$ & $\%$ & \\
\hline Jordan & & & \\
\hline Host country & 50.5 & 8.3 & 2002 national survey, age $>18$ yrs \\
\hline Palestine refugees ${ }^{\mathrm{a}}$ & 48.0 & 8.4 & UNRWA 2007 \\
\hline Lebanon & & & \\
\hline Host country & 60.7 & 46.9 & 1997 national survey, age $>19$ yrs \\
\hline Palestine refugees ${ }^{\mathrm{a}}$ & 59.5 & 39.9 & UNRWA 2007 \\
\hline Gaza Strip and West Bank & & & \\
\hline Host country & 20.0 & 18.0 & EMRO country profile 2004 \\
\hline Gaza: Palestine refugees ${ }^{a}$ & 49.5 & 0.6 & UNRWA 2007 \\
\hline $\begin{array}{l}\text { West Bank: Palestine } \\
\text { refugees }^{\mathrm{a}}\end{array}$ & 43.7 & 6.1 & UNRWA 2007 \\
\hline Syrian Arab Republic & & & \\
\hline Host country (subnational) & 62.0 & 21.0 & 2004 Aleppo survey, age 18-65 yrs \\
\hline Palestine refugees ${ }^{\mathrm{a}}$ & 57.1 & 15.3 & UNRWA 2007 \\
\hline $\begin{array}{l}\text { Israel } \\
\text { Eastern Mediterranean }\end{array}$ & 38.6 & 22.1 & 2001 national survey, age $25-64$ yrs \\
\hline Region & 34.2 & 8.7 & $1998 \mathrm{WHO}$ \\
\hline
\end{tabular}

UNRWA = United Nations Relief and Works Agency for Palestine Refugees in the Near East; EMRO=World Health Organization Regional Office for the Eastern Mediterranean; WHO=World Health Organization a Data refer only to the Palestinian refugees screened for noncommunicable diseases at UNRWA health centres. 
The long-term commitment to the refugee population it serves, its growing social and economical vulnerability and the financial constraints of the Agency itself pose sustainability issues. Moreover the changing health needs of the refugees need to be addressed, and this often involves creating or expanding services. Improving communication among fields and programmes will also be essential to coordinate activities in view of the Agency's complexity and the diverse countries/territories in which it operates.

\section{Limitations of the study}

The paper presents the results of a caseseries study. The study design created certain selection biases. First, screening was conducted only among those accessing UNRWA health clinics and therefore the screened population may not be representative of the Palestine refugee population served by UNRWA. The main consequence of this was an imbalance in the number of males and females sampled in the study. A second selection bias might have been introduced by the screening criteria. While being older than 40 years justified screening per se, screening of younger people was encouraged only when other risk factors were present. This may have led to an overestimate of the role of age as a risk factor for both hyperglycaemia and hypertension. This limits the possibility of extrapolating the results to the general UNRWA screened population. However, the high numbers enrolled in our study increases the credibility of the results, and the first selection bias was partly addressed in the analysis.

A third selection bias may have been introduced during the data collection. Although homogeneous screening criteria were adopted, the screening process appears to have been adjusted differently, with correspondingly different outcomes, among different fields. For example, Gaza had the highest proportion of persons screened under age 40 years, the highest proportion of cases with a positive family history and the highest proportion of screened people actually diagnosed with a NCD. This poses questions about the comparability of the results among fields and their extrapolation to the refugee population as a whole.

The possibility of conducting operational research in 5 countries/territories at the same time is both a great asset and challenge for UNRWA and more efforts are needed to standardize programme implementation and data collection in different fields.

\section{Acknowledgements}

The work was performed and financially supported by the United Nations Relief and Works Agency for Palestine Refugees in the Near East (UNRWA).

\section{References}

1. Boutayeb A, Boutayeb S. The burden of non communicable diseases in developing countries. International journal for equity in health, 2005, 4(1):2.

2. International Diabetes Federation [website] (http://www.diabetesatlas.org/content/what-is-diabetes, accessed 10 March 2010).

3. Alwan A. Noncommunicable diseases: a major challenge to public health in the region. Eastern Mediterranean health journal, 1997, 3:6-16.

4. Khatib O. Noncommunicable diseases: risk factors and regional strategies for prevention and care Eastern Mediterranean health journal, 2004, 4:778-88.

5. Report on the consultation on establishing an integrated regional non communicable diseasenetwork. Cairo, Egypt24-26June2001. Cairo, World Health Organization Regional Office for the Eastern Mediterranean, 2001 (WHO-EM/NCD/027/E/L) (http://
whqlibdoc.who.int/emro/2001/WHO-EM_NCD_027_E_L. pdf, accessed 8 February 2010).

6. World Health Organization Regional Office for the Eastern Mediterranean [website] (http://www.emro.who.int/ncd/ pdf/Diabetes_in_EMRO.pdf, accessed 10 March 2010).

7. International Diabetes Federation [website] (http://www. diabetesatlas.org/content/middle-east-and-north-africa, accessed 10 March 2010).

8. Allgot B et al. Diabetes atlas, 2nd ed. Brussels, International Diabetes Federation, 2003.

9. Disease Control Priority Project. Non-communicable diseases. Washington DC, International Bank for Reconstruction and Development/World Bank, 2006.

10. Musaiger AO. Overweight and obesity in the Eastern Mediterranean Region: can we control it? Eastern Mediterranean health journal, 2004, 10(6):789-93. 